Antropología Cuadernos de Investigación, núm. 15, julio-diciembre 2015, pp. 123-125

\title{
Estudios Multidisciplinarios en cinco espacios prehispánicos tardíos del Ecuador, Instituto Nacional de Patrimonio Cultural, 2014.
}

$\mathrm{E}$ 1 periodo prehispánico generalmente es organizado en una clasificación cronológica aparentemente rígida que periodiza la historia anterior al arribo de campañas europeas a los territorios del actual Ecuador. Como es preciso señalar, por excelencia la arqueología, es la encargada de estudiar a los vestigios materiales de las sociedades pasadas para llegar a una interpretación de las mismas. Uno de los resultados de las investigaciones son los periodos en los que actualmente comprendemos, criticamos y debatimos la ubicación temporal de los elementos del registro arqueológico, que es el objeto mismo de la arqueología. En concordancia con ello se da inicio a la periodización con el "Arcaico que en el 6000 a.C." (Salazar, 2008: 35) y terminaría con el fin del periodo de Integración con "la guerra civil incaica hacia 1529 y la conquista española" (Udo Oberem, 1996: 145).

Estudios multidisciplinarios en cinco espacios prehispánicos tardíos del Ecuador, es un producto del proyecto "Principio culturales y tecnológicos: valoración y uso en el Ecuador actual". Este fue ejecutado en cinco lugares diferentes distribuidos en la costa y sierra ecuatoriana, bajo la dirección del Dr. Napoleón Almeida y un equipo multidisciplinario de trabajo. Se abordan los diferentes espacios desde una perspectiva: geográfica, histórica, socio-cultural, y arqueológica, incluyendo también un acercamiento desde el paisaje cultural. Por ello los datos presentados en la obra obedecen hacia la conceptualización del periodo tardío, el cual se evidencia en el registro arqueológico de todos los sitios, la factibilidad para estudios etnohistóricos a partir de fuentes primarias y secundarias, y el diagnóstico de técnicas y prácticas ancestrales que pudieran estar vigentes hasta nuestros días.

El periodo más tardío de la historia prehispánica es conocido como Integración "800-1500 d.C." (Valdéz, 2008: 868), en donde se evidencia la adhesión de los territorios septentrionales al Tahuantinsuyo. En este aspecto los sitios investigados en el proyecto guardan la relación de obtener fechados que los ubicarían a periodos correspondientes al periodo de Integración. Sin embargo también se presenta los contextos culturales hallados en estos sitios que corresponden a periodos anteriores.

El aspecto geográfico es abordado con mucha claridad y calidad. Los mapas temáticos que se presentan en todos los capítulos de la obra son de mucha claridad. Se maneja de manera consistente datos ilustrativos en la leyenda y simbología además de darnos una clara referencia de escalas. La cartografía también presenta datos estadísticos que reflejan de manera ordenada y coherente los datos presentados en la redacción del contexto geográfico en cada uno de los sitios. Además cabe destacar que las fuentes aportan datos referenciales para un mayor entendimiento 
del espacio descrito. La ventaja de la publicación en una edición full color, sin duda muestra con mayor detalle todos los aspectos de interés.

Las fuentes primarias y secundarias utilizadas en el estudio de la perspectiva histórica, son el reflejo del trabajo de búsqueda, consulta, sistematización, interpretación y análisis del material archivístico de los sitios contemplados. En cuanto a esto debemos señalar que las fuentes etnohistóricas no siempre nos garantizan un entendimiento completo del contexto a estudiar, sino que obligan a un arduo trabajo. Por ello la información se presenta a manera regional, por que varios archivos están centralizados y se encuentran en cabeceras cantonales y lugares distantes al sitio en mención. Además cabe destacar que las menciones en crónicas, documentos legales y registros son puntuales y escasas por lo que la información se complementa con otras fuentes que ayudan a profundizar el entendimiento de la época.

El trabajo arqueológico se muestra a manera de informes de labores realizados en la investigación, se presenta metodología, secciones investigadas, material recolectado análisis y conclusiones. En cuanto a la investigación arqueológica cabe destacar que se realizó de manera independiente por grupos específicos de trabajo que se dedicaron al estudio de un sitio en particular. La conceptualización se da en base a objetivos planteados deductivamente que se encasillarían en etapas posteriores a la temática central del proyecto de investigación. Algunos datos deben ser revisados con detenimiento ya que al tratarse de nuevos hallazgos nos ofrecen nuevos datos de zonas que han sido estudiadas con anterioridad. Los resultados obedecen a los objetivos planteados y presentan una fuente de información para desarrollar críticas y generar resultados con mayor dimensión.

Dentro de la búsqueda de saberes ancestrales, se realiza un diagnóstico de las áreas de interés que mediante prácticas etnográficas recolecta información con este objetivo. Es preciso señalar que el registro se realizó en base a un trabajo de gran duración que se concentró en observar las técnicas cotidianas de los pobladores de los territorios de interés y un posible nexo con las prácticas ancestrales realizadas en tiempos prehispánicos. Como tal se señalan que algunas de ellas no podrían estar relacionadas directamente, logrando un enfoque desde la práctica sociocultural de los habitantes actuales y una posible relación con las sociedades prehispánicas que habitaron dichos espacios. Teniendo por sentado la influencia perceptible o no de la organización social anterior que influye en la conformación de las poblaciones actuales.

El ejercicio del lector es el de abstraer la gran cantidad de datos presentados en este trabajo y poder enfocarlos en ejercicios críticos que fortalezcan la comprensión de sitios específicos y su contraste para una influencia regional. El trabajo interdisciplinario presentado aquí, es llamativo, no presenta una compaginación exacta de las perspectivas mencionadas pero si expresan datos funcionales para la comprensión del mismo. En cuanto a la edición, se debe señalar que el trabajo creativo presenta un producto estéticamente agradable y novedoso sin embargo al tratarse de un tiraje limitado de 1000 ejemplares, podría ser difícil de conseguir la versión impresa, por ello recomendamos su lectura en la versión digital disponible en el portal web del Instituto Nacional de Patrimonio Cultural. Recomendamos la lectura de esta obra y dado que en su introducción se plantea como un recopilado de resultados preliminares esperaremos ansiosos su siguiente etapa. 


\section{Referencias}

Oberem, Udo. 1996, "El periodo incaico en el Ecuador”, en: Enrique Ayala Mora (Ed.) Nueva Historia del Ecuador, Volúmen 2, Época Aborígen II. Quito: Corporación Editora Nacional. Pag: 135-162.

Salazar, Ernesto. 2008, "El Proceso Cultural en el Ecuador Aborígen y en América”, en: Ayala Mora, Enrique (Ed.) Nueva Historia del Ecuador, Volúmen 1, Época Aborígen I, Corporación Editora Nacional, Quito, pp: 33-59.

Valdéz, Francisco. 2008, "Inter-Zonal Relationships in Ecuador", en: Silverman \& Isbell (Eds.) Handbook of Southamerican Archaeology. Cap: 43. Springer Science. pp: 865-887. 